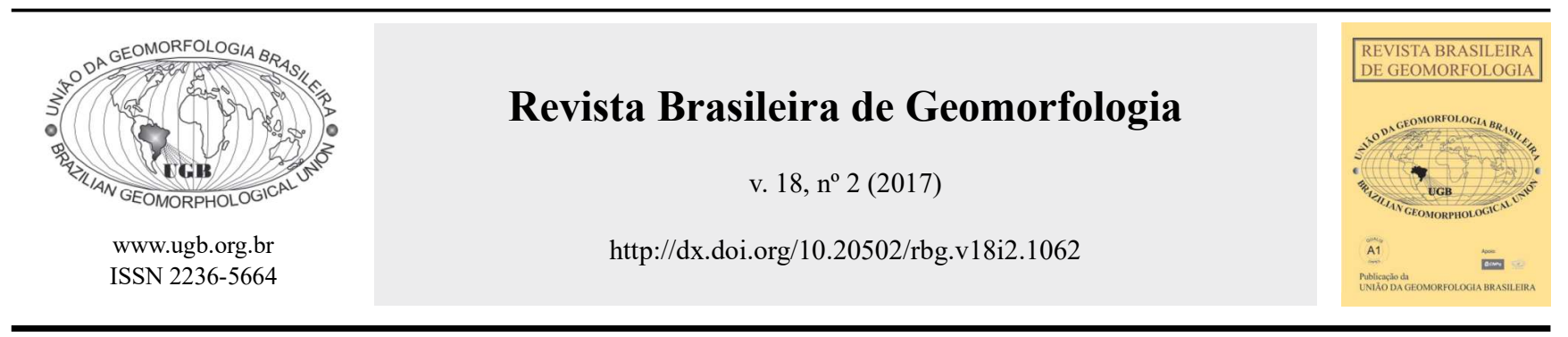

\title{
CARACTERIZAÇÃO MORFOLÓGICA E DINÂMICA AMBIENTAL DAS MARMITAS (WEATHERING PIT) NO DISTRITO DE FAZENDA NOVA, PERNAMBUCO - NORDESTE DO BRASIL
}

\section{MORPHOLOGICAL CHARACTERIZATION AND ENVIRONMENTAL DYNAMIC OF WEATHERING PITS IN FAZENDA NOVA DISTRICT, STATE OF PERNAMBUCO, NORTHEAST OF BRAZIL}

\author{
Danielle Gomes da Silva \\ Departamento de Ciências Geográficas, Universidade Federal de Pernambuco \\ Av. Acadêmico Hélio Ramos, s/n, Recife, Pernambuco. CEP: 50740-530. Brasil \\ Email:dannyavlis@yahoo.com.br
}

Antonio Carlos de Barros Corrêa

Departamento de Ciências Geográficas, Universidade Federal de Pernambuco Av. Acadêmico Hélio Ramos, s/n, Recife, Pernambuco. CEP: 50740-530. Brasil

Email:dbiase2001@terra.com.br

Rodrigo de Freitas Amorim

Departamento de Geografia, Universidade Federal do Rio Grande do Norte Campus Universitário, s/n, Natal, Rio Grande do Norte. CEP: 59078-900. Brasil

Email: rodrigofba@yahoo.com.br

Informações sobre o Artigo

Recebido (Received):

17/04/2016

Aceito (Accepted):

$11 / 11 / 2016$

\section{Palavras-chave:}

Marmita; Dinâmica

Geomorfológica; Semiárido;

Nordeste Do Brasil.

\section{Keywords:}

Weathering Pit; Geomorphological Dynamics; Semi-Arid Climate; Northeastern Brazil.

\section{Resumo:}

As depressões fechadas - marmitas -, sobre litologias cristalinas são encontradas em diferentes regiões do planeta. No Estado de Pernambuco as marmitas foram registradas em 37 municípios. Assim, como vem sendo trabalhado em outras regiões no semiárido do Nordeste brasileiro, as marmitas têm servido como fontes de dados para a reconstrução geomorfológica recente da paisagem, a partir do reconhecimento de eventos pretéritos encontrados no registro sedimentar que as preenchem. Desta forma, o trabalho objetiva interpretar, através da análise morfológica dos compartimentos de relevo, a gênese e dinâmica do relevo na área de Fazenda Nova, município de Brejo da Madre de Deus - Pernambuco. As marmitas na área em estudo geralmente estão associadas aos inselbergs de um granito pórfiro, em zona de intercessão de linhas de fraturas e morfologicamente restrita aos pedimentos intermontanos de topografia marcadamente plana, nas proximidades dos "knickpoints" das unidades de encostas. O depósito que preenche a marmita da propriedade Incó foi derivado por sedimentação gravitacional do tipo fluxo de detrito, sob condições torrenciais, evidenciando que este registro teve sua gênese associada a ciclos de pedogênese/morfogênese sob diversas combinações de semiaridez atuantes na área desde o penúltimo máximo glacial. 


\begin{abstract}
:
Closed depressions - weathering pits -, developed on crystalline lithology are found in many regions of the planet. In the State of Pernambuco, weathering pits were found in 37 municipalities. As they are being studied in other sectors of the semiarid region of Brazil, weathering pits have served as important data sources for the reconstruction of recent geomorphological landscape histories, based on the study of their sedimentary infill. In this regard, this work aims at interpreting, by means of the morphological analysis of landforms, the genesis and dynamics of relief in the area of Fazenda Nova, Brejo da Madre de Deus municipality, State of Pernambuco. Weathering pits in the study area are generally associated to coarse grained granite inselbergs, occurring along the intersections of fracture lines, and morphologically restricted to intermontane pediments of flat topography in the vicinity of hillslope knick points. The sedimentary infill of Incó weathering pit derived from unchanneled debris flows, formed under torrential conditions, thus showing that this aggradational record is related to alternating cycles of pedogenesis/ morphogenesis under differing levels of semi-aridity occurring in the area since the penultimate glacial maximum.
\end{abstract}

\section{Introdução}

Várias são as referências na literatura geológica à cerca das depressões fechadas disseminadas sobre litologias cristalinas. Até o presente, são registradas presenças de depressões fechadas em 37 municípios pernambucanos (Barreto et al. 2004), entretanto, os estudos realizados concentram-se sob os aspectos paleontológicos e arqueológicos dos materiais de preenchimento, e ainda pouco se sabe a respeito dos processos associados à gênese $\mathrm{e}$ evolução dessas feições geomorfológicas.

Alguns autores classificam as depressões conforme a sua ocorrência em superfície: weatheringpans, rock basing, rock roles, granite pits, para superficies horizontais; armchairhollow, para superfícies inclinadas; e tafone, para superfícies verticais (TWIDALE, 1982; VIDAL ROMANÍ \& TWIDALE, 1998, BIGARELLA, 1994). Entretanto, em distintas partes do mundo, tais feições são denominadas como gnammas, na literatura australiana; tanques e vasquesrocheuses, na França; pías, pilas e pilacones, na Espanha; caldeirões, poços, marmitas e oriçangas, no Brasil (VIDAL ROMANÍ \& TWIDALE, op.cit).

Embora tais feições sejam comumente referidas na literatura regional como "cacimbas" (ROLIM, 1974), estas serão tratadas neste estudo como "marmitas", do termo inglês "weathering pits", que devido à grande aceitação internacional, sobrepõem-se a todos os termos regionalistas até o momento atribuído a tais formas.

Apesar das marmitas serem tratadas como feições comuns e exclusivas de regiões áridas e semiáridas (CAMPBELL, 1997; GUTIÉRREZ, 2005; VIDAL ROMANÍ \& RODRIGUES, 2007; NETOFF \&CHAN, 2009), estas feições desenvolveram-se em diversos contextos climáticos do mundo, ainda que, em regiões glaciares, os estudos das marmitas estejam voltados ao entendimento de sua formação. Entretanto, no interior semiárido do Nordeste brasileiro as marmitas têm servido como fontes de dados para a reconstrução geomórfica recente da paisagem, a partir do reconhecimento de eventos pretéritos encontrados no registro sedimentar que as preenchem.

Diante do exposto acima, este trabalho teve por objetivo interpretar através da análise morfológica das marmitas e seu depósito de preenchimento, a gênese e dinâmica do relevo da área de Fazenda Nova (PE). Assim sendo, buscou-se pela interpretação dos fatos geomorfológicos e dos seus materiais constituintes, reconstruir a participação dos agentes endógenos e exógenos sobre o modelado que ainda mantém estreitos vínculos com a paisagem hodierna.

Fazenda Nova localiza-se no setor centro-leste do estado de Pernambuco, no município de Brejo da Madre de Deus, situado na microrregião do Vale do Ipojuca, distando cerca de $180 \mathrm{Km}$ da cidade do Recife (Figura 1).

Morfologicamente, a área apresenta-se como uma depressão inter-planáltica, largamente aplainada e pouco dissecada, decorrente das diversas fases de denudação pós-cretácea da Borborema. Os pedimentos se elevam em pequenos patamares sem que haja uma ruptura brusca de gradiente condicionada por uma trama de falhas, ocasionando o confinamento de pequenos depósitos em alvéolos restritos ao ambiente fluvial.

A uniformidade topográfica da superfície dos pedimentos só é interrompida pelos relevos residuais em forma de inselbergs e alinhamentos de serras, com altitudes variando de 500 a mais de $900 \mathrm{~m}$, testemunhos das antigas superfícies cenozóicas. Os relevos residuais apresentam-se orientados segundo as direções preferen- 
ciais da estrutura regional, NE-SW, formando vales profundos e encaixados, com controles estruturais indicando movimentação tectônica possivelmente neo-cenozóica associada à reativação de antigas estruturas com descida do nível de base a sudoeste e subida a noroeste, ocasionando perda de nascentes fluviais e captura de drenagem.

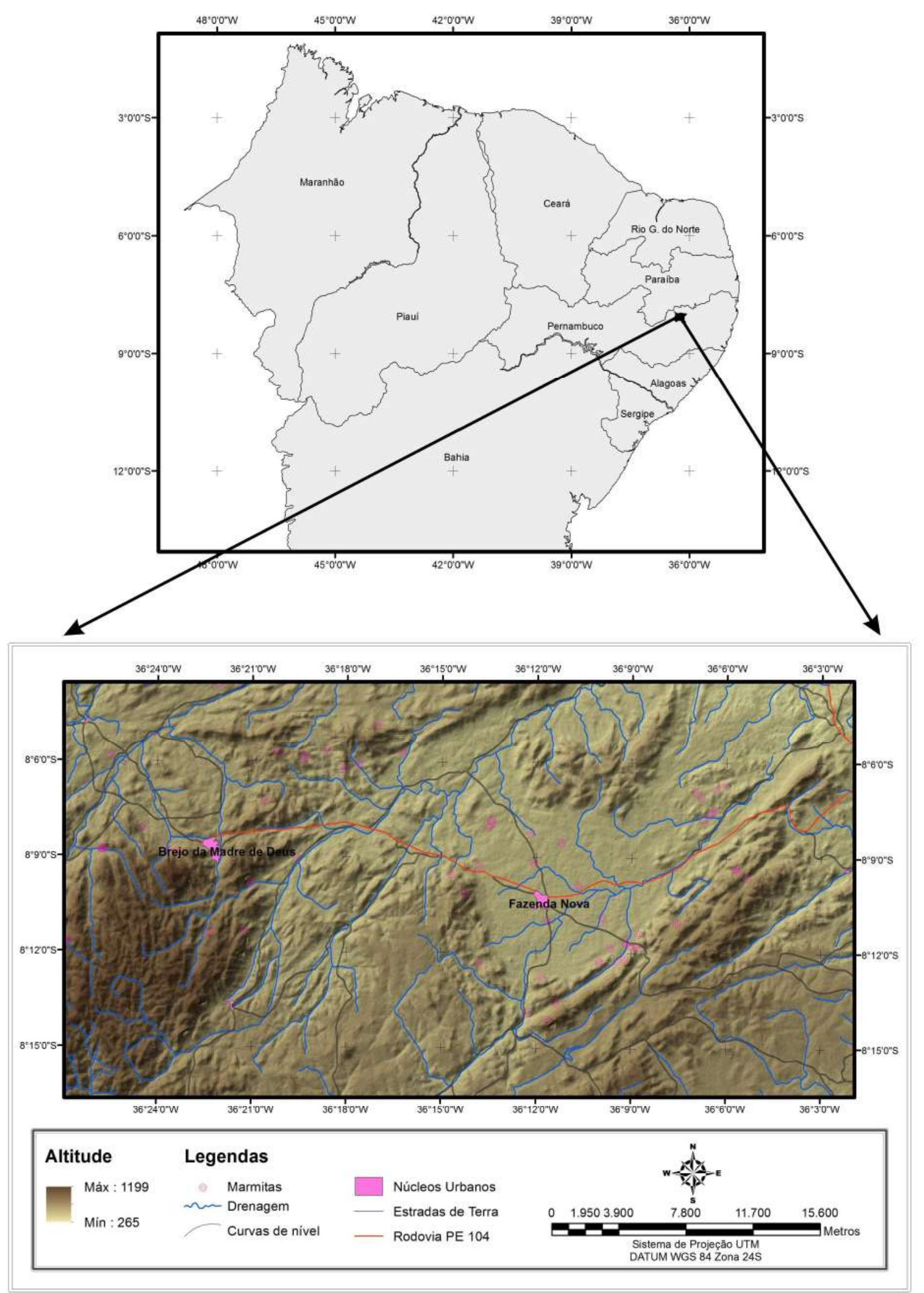

Figura 1-Localização da área de estudo, distrito de Fazenda Nova/PE. Fonte: EMBRAPA (2001) 


\section{Processos De Origem E Evolução Das Microfor- mas Graníticas: As Marmitas De Dissolução}

As rochas alteram-se e são erodidas em velocidades diferentes. As rochas ígneas sofrem uma ação muito lenta das intempéries, principalmente em ambientes áridos e semiáridos, onde a alteração destas ocorre devido à ampla variação diária e sazonal da temperatura e umidade.

As marmitas são depressões escavadas na rocha fresca, que devido a controles estruturais, podem apresentar contornos irregulares. Tipicamente descritas em granitos, por muito tempo sua origem foi atribuída à ação humana, associada a cerimônias druídicas (WORTH, 1953). Entretanto, uma procedência antropogênica para tais formas foi descartada, tendo em vista que um desenvolvimento a partir do ataque da umidade em áreas de fraqueza litoestrutural foi apresentado por diversos autores como a explicação mais plausível para origem das marmitas.

Christofoletti (1981), tratando de formas topográficas erosivas em leitos rochosos, atribuiu a origem das marmitas a depressões escavadas pela abrasão giratória de seixos ou blocos, rotacionados pela energia da água corrente. Bigarella (1994), entretanto, definiu as "panelas de dissolução" como uma feição de intemperismo de pequeno porte que se desenvolve por coalescência lateral dos alvéolos ${ }^{1}$.

Evidências colhidas em literatura especializada (TWIDALE, 1982; CAMPBELL, 1997; VIDAL ROMANÍ \& TWIDALE, 1998; VIDAL ROMANÍ \& RODRIGUEZ, 2007) apresentam os processos tectônicos como um fator importante na formação das marmitas. A deformação de blocos falhados produziria movimentos tectônicos diferenciados que alteraria o grau de resistência litológica. Esta diferenciação estrutural e litológica, ocorrendo por longos períodos, originaria em subsuperfície a alteração geoquímica da rocha, com formação do front de intemperismo. Sendo assim, as características estruturais e geoquímicas das rochas determinariam o grau e intensidade da alteração, produzindo a formação das marmitas de dissolução.

Segundo Vidal Romaní \& Twidale (1998), os fatores tectônicos explicariam os casos de alinhamento das marmitas ao longo das fraturas, assim como a asso- ciação imediata destas em ambos os planos de fratura, muito frequentes nos maciços graníticos diaclasados e deformados. Ainda segundo os autores, nas pequenas marmitas assim formadas, a acumulação periódica de água, após a sua exposição em superfície a partir dos ciclos erosivos, atuaria na alteração dos silicatos, principalmente micas e feldspatos, dando forma às marmitas.

Estudos recentes realizados por Shakesby et al. (2006) apresentam outro fator que pode influenciar a localização e início de formação das marmitas, a concentração de tensões em determinados pontos do maciço rochoso. Para os autores, as marmitas podem ser formadas a partir de processo de alteração de um maciço rochoso segundo seu sistema ortogonal de descontinuidade. Trata-se de trocas no sistema de apoio entre blocos graníticos separados por descontinuidades estruturais, que permite a circulação da água, favorecendo assim a alteração da rocha.

Entretanto, este processo de alteração não é homogêneo e ocorre em diferentes pontos do plano de descontinuidade. Dessa maneira, o peso, que inicialmente encontrava-se distribuído ao longo de toda superfície dos blocos, se concentrará nos pontos onde há contato entre a rocha sã, uma vez que o módulo de compressibilidade da rocha não alterada e do regolito são diferentes. A consequência imediata deste processo será uma distorção na estrutura mineral da rocha tornando-o mais susceptível ao intemperismo e a formação das marmitas de dissolução.

A fim de corroborar o pressuposto de desenvolvimento das marmitas a partir da concentração de tensões em maciços graníticos, Vieira (2008) mediu a resistência de rochas granitoides na Serra de Montemuro em Portugal. Tal estudo revelou que os afloramentos graníticos com ausência de marmitas correspondiam às superfícies mais elevadas e atingiram o valor de $\mathrm{R}^{2}$ (ressalto de massa) superiores a 55, o que reflete uma superfície rochosa maciça, coesa e mais resistente as ações físicas e químicas de intemperismo. Por outro lado, os afloramentos graníticos com desenvolvimento de marmitas apresentaram valores claramente inferiores de $\mathrm{R}$, em torno de 45 , o que conjectura uma fragilidade superior dos afloramentos face aos processos que atuam sobre estas para a sua alteração.

\footnotetext{
${ }^{1}$ De acordo com Bigarella (1994), os alvéolos caracterizam-se por pequenas reentrâncias de poucos milímetros a alguns centímetros de diâmetros e profundidade, relacionada à ação solvente das águas paradas.

${ }^{2}$ Segundo Vieira (2008), os valores obtidos correspondem ao valor de ressalto da massa, que se traduzem pelo valor R ("reboundvalues" - "R-values"). A análise destes valores compreende o cálculo da média dos valores de resistência obtidos pelo esclerómetro Schmidt Hammer.
} 
Embora a origem e formação das marmitas de dissolução seja um tema bastante debatido, uma tentativa de definir o tempo de evolução das marmitas é por natureza uma tarefa complexa, já que os processos externos e internos sofridos pela rocha onde as mesmas são esculpidas torna-se um fator limitante à obtenção de uma idade precisa para a sua formação (PARSONS, et al., 2005); embora vários estudos sugiram uma evolução rápida dessas feições em cerca de centenas a milhares de anos no nordeste brasileiro (ROLIM, 1974; PAULA-COUTO, 1980). Entretanto, pesquisas realizadas por Silva (2008) e Oliveira et al. (2009), tendo por base as datações da megafauna pleistocênica preservadas no interior das marmitas de dissolução no sertão nordestino, apontam para uma origem de tais feições anterior aos últimos $100 \mathrm{Ka}$.

Em ambiente periglacial, uma formação recente para as marmitas foi constatada por Dominguéz-Villar (2006). Datações realizadas em depósitos de morainas em Torres del Paine, Patagonia Meridional, onde as marmitas foram encontradas, indicam que o desenvolvimento destas feições foi iniciado a aproximadamente $0,6 \mathrm{Ka}$ a $1,25 \mathrm{Ka}$, seguindo a cronologia glacial para a área.

Apesar de, em algumas regiões, os fatores climáticos exercerem controle para o desenvolvimento das marmitas, Twidale (1982) assegura que a composição e estrutura da rocha influenciarão diretamente em sua taxa de evolução e diferenciação de formas.

\section{Materiais e Métodos}

O trabalho de campo se concentrou em Fazenda Nova, distrito do município de Brejo da Madre de Deus. As marmitas foram priorizadas como unidade morfoestratigráfica a serem identificadas e pesquisada. Estas foram georreferenciadas com GPS topográfico, inicialmente pelas informações obtidas a partir do material bibliográfico disponível e atualizadas a partir de trabalhos de campo. A análise morfológica das marmitas em Fazenda Nova foi realizada seguindo a proposta de Gutiérrez (2005), que classifica as marmitas segundo a sua seção transversal.

Após esta etapa, a marmita da Fazenda Logradouro foi escolhida para datação por luminescência opticamente estimulada. Tal escolha se deu em virtude desta marmita se encontrar preenchida por sedimento e apresentar em seu interior ossos da megafauna pleisto- cênica. A coleta para datação foi realizada em tubos de PVC de cor preta, com $40 \mathrm{~cm}$ de comprimento e $5 \mathrm{~cm}$ de diâmetro. Os tubos foram introduzidos no sedimento evitando ao máximo a exposição à luz solar sendo fechados com tampas preta de borracha bem ajustadas. $\mathrm{O}$ teor de umidade dos sedimentos foi preservado para medição posterior em laboratório, para tanto, as amostras foram cuidadosamente embaladas em filme plástico, evitando assim qualquer perda de umidade durante o transporte.

O método de datação por luminescência abrange uma gama de técnicas baseadas no acúmulo de cargas radioativas produzidas por uma população de elétrons aprisionados em minerais cristalinos. As datações de sedimentos por luminescência opticamente estimulada (LOE) foram realizadas na empresa Datação, Comércio \& Prestação de Serviços, em São Paulo. Este método é capaz de estabelecer o período de tempo transcorrido desde que a população aprisionada de elétrons foi liberada pela última vez.

Sendo assim, os tubos de PVC são abertos na extremidade interna de inserção indicado no ato da coleta, em ambiente de luz vermelha. Posteriormente, os sedimentos passam por um tratamento químico com $\mathrm{H}_{2} \mathrm{O}_{2}$ $(20 \%), \mathrm{HF}(20 \%)$ e finalmente $\mathrm{HCl}(10 \%)$, sendo as lavagens intermediárias efetuadas com água destilada.

Após tratamento químico, as amostras são secas e peneiradas, separando a fração granulométrica na faixa de 100-160 $\mu \mathrm{m}$ (100-60 Tyler), obtendo assim material natural (quartzo/feldspato) isentos de materiais orgânicos e/ou metais pesados, e com granulometria bem homogênea.

A partir da amostra de material natural, uma porção é separada e submetida à radiação solar por um período de aproximadamente 20 dias para decaimento residual (TL / OSL). Desta porção são separadas várias amostras que são irradiadas (fonte de ${ }^{60} \mathrm{Co}$ (455Ci)) em várias doses pré-definidas (Gy), que devem estar próximas a dose acumulada natural para montagem da curva de calibração.

O protocolo utilizado para a datação foi o SAR. Este protocolo é seguido para a determinação de uma idade média dentre pelo menos 10 a 20 alíquotas, ou seja, são construídas de 10 a 20 curvas de calibração, onde são encontradas de 10 a 20 idades, sendo possível a construção de um histograma de idades e interpretação da variação de idades em cada amostragem. 


\section{Classificação Morfológica das Marmitas no Dis- trito de Fazenda Nova}

Após a sua exposição em superfície, as marmitas podem evoluir para diferentes tipos morfológicos. Algumas são fortemente influenciadas por descontinuidades, possuindo contornos angulares ou resultando da coalescência de duas ou mais formas individuais. As marmitas variam entre circulares, ovais, elípticas e ocelares, normalmente são rasas e apresentam fundo plano.

Geologicamente, o corpo granítico que perfaz as formas em estudo é o Batólito Brejo da Madre de Deus, parte integrante do Batólito Caruaru-Arcoverde, o maior corpo da associação cálcio-alcalina de alto potássio da Província Borborema. Petrograficamente apresentam textura grossa a porfirítica, onde se destaca cristais de feldspato potássico com até $8 \mathrm{~cm}$ de comprimento e mineralogicamente esta fácies é constituída além de feldspato potássico, por plagioclásio e quartzo como minerais essenciais. Os máficos dominantes são biotita, anfibólio e, em menor quantidade, titanita. A borda sul do batólito é marcada pelo Lineamento Pernambuco, uma estrutura originada em um episódio extensional no ciclo Brasiliano (650-540 Ma) de direção E-W que atravessa todo o estado, iniciando-se na zona costeira de Recife, separando-o em dois domínios: o domínio ao sul, denominado de Externo ou Meridional, e o domínio ao norte, conhecido como Transversal (Figura 2).

As marmitas na área em estudo geralmente estão associadas aos inselbergs, em zona de intercessão de linhas de fraturas e morfologicamente restrita aos pedimentos intermontanos de topografia marcadamente plana, nas proximidades dos "knickpoints" das unidades de encostas (Figuras 03). Estas apresentam, algumas vezes, em seu eixo deposicional solos do tipo vertissolo constituindo seu material de preenchimento mais superficial, em boa sintonia com as condições semiáridas vigentes. Em subsuperfície observam-se níveis de sedimentação grossa, intercalados por sedimentos arenosos contendo grânulos de seixos. A repetição cíclica dos depósitos sugere fases alternadas de ambientes ora dominados por precipitações torrenciais - fluxo de detritos - ora mais secos - nódulos de carbonato de cálcio.

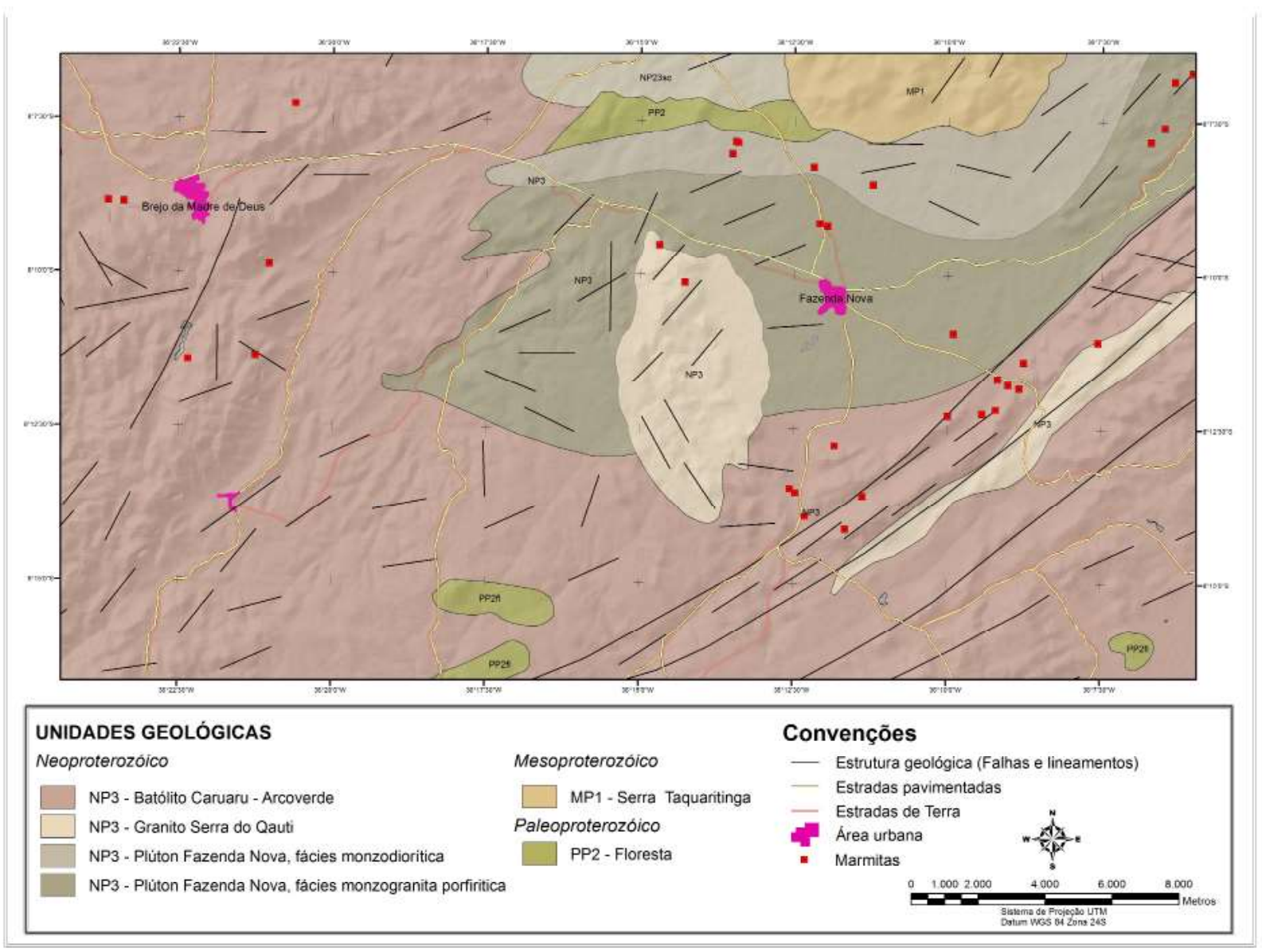

Figura 2 - Mapa geológico da área de Fazenda Nova e a distribuição de ocorrência de marmitas classificadas. Fonte: Gomes (2001) 


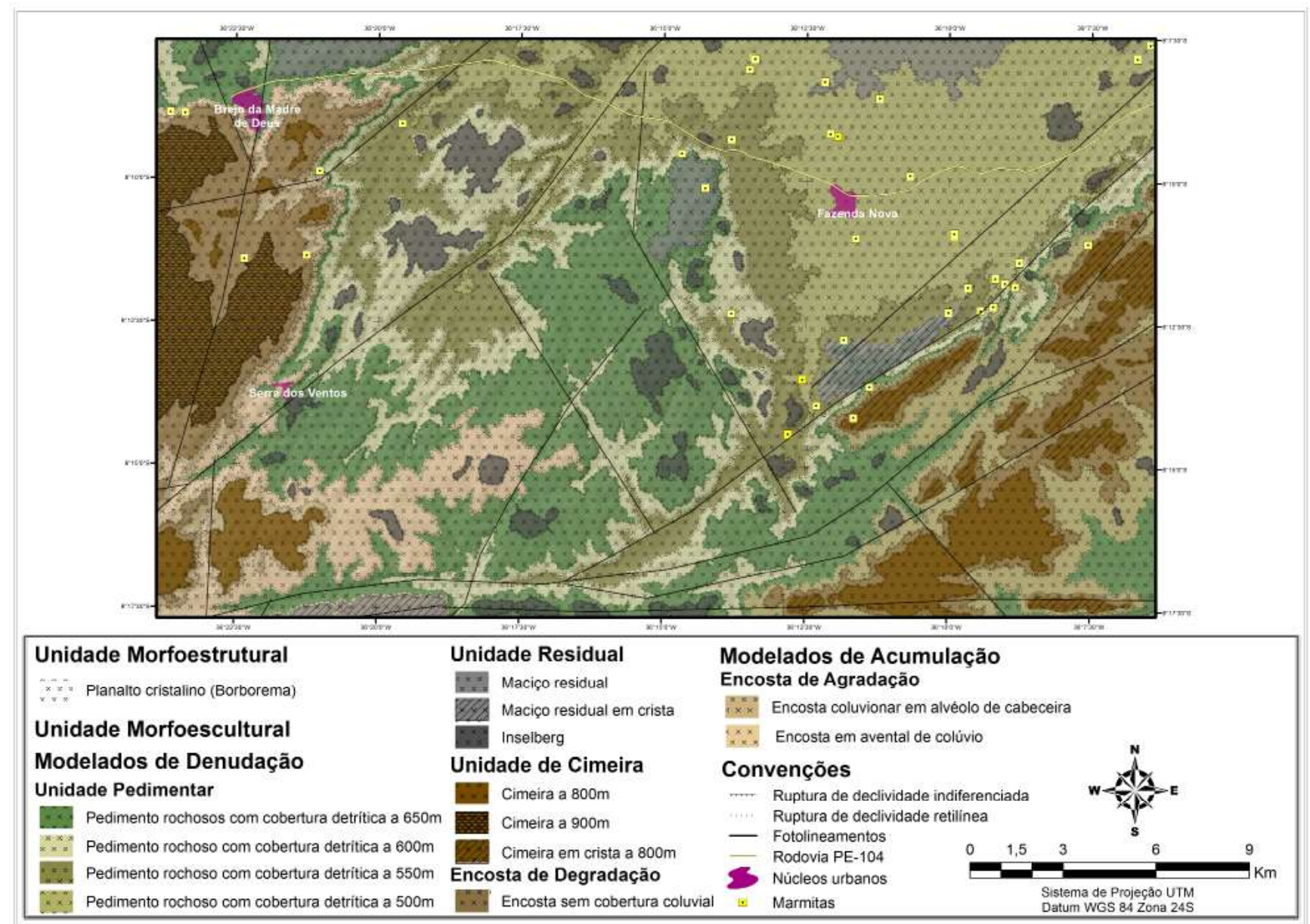

Figura 3 - Mapa geomorfológico da área de Fazenda Nova e distribuição de ocorrência de marmitas classificadas. Fonte: Os autores.

Seguindo a proposta de Gutiérrez (2005), as seguintes morfologias foram descritas para as marmitas no distrito de Fazenda Nova:

1. Marmita com borda suave: São menos profundas e possuem fundo plano (Figura 4). São circulares, elípticas ou poligonais, com contornos suaves e regu- lares. Habitualmente não possuem exutório definido e o transbordamento da água se produz ao longo de todo o contorno da cavidade. Em alguns casos, este tipo de marmita encontra-se unida a outros por canais ou ranhuras formando parte de uma incipiente rede de drenagem.

\section{A}
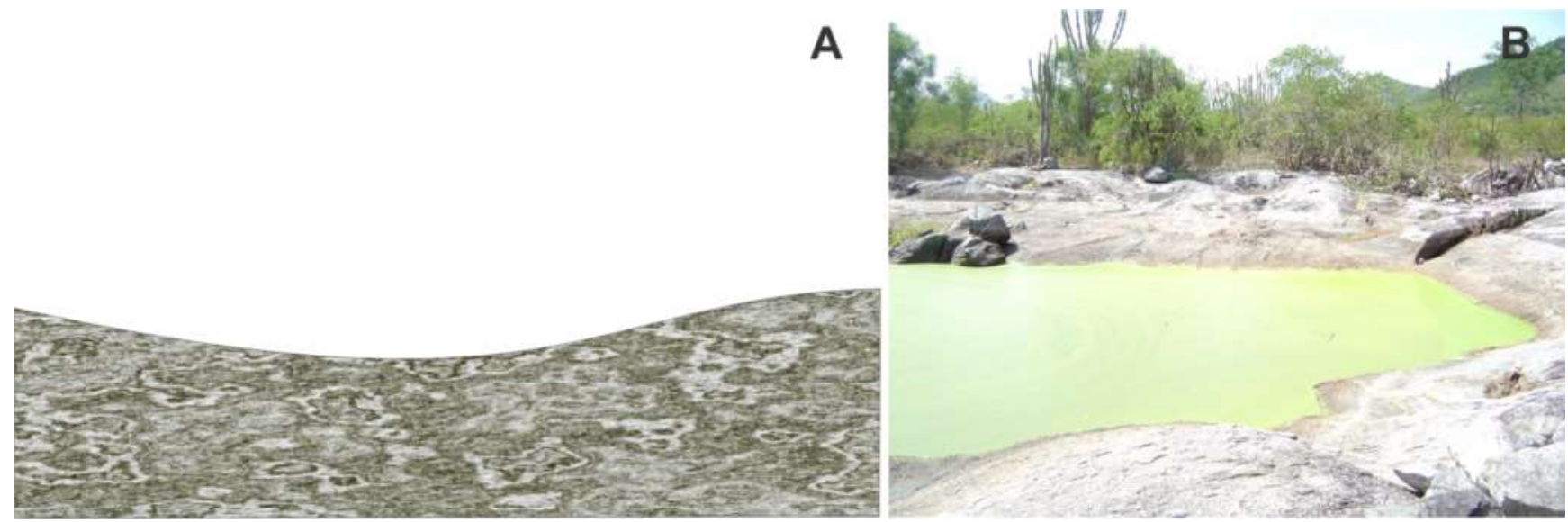

Figura 4-Marmita com bordas suaves. A) Seção esquemática; B) Marmita em Fazenda Nova. 
2. Marmita com morfologia em caldeirão ou poço: Sua forma varia, embora geralmente apresentem morfologia ocelar com uma seção transversal retangular. Em alguns casos, suas extremidades produzem descamação quebrando uma de suas bordas permitindo, eventualmente, a drenagem da marmita. A morfologia de suas paredes sugere que sua formação ocorreu a partir da ação do turbilhonamento da água em momentos de fortes precipitações. Geralmente esse tipo de marmita encontra-se preenchida por sedimentos, de modo que sua morfologia só é perceptível após a remoção do seu material de preenchimento (Figura 5).

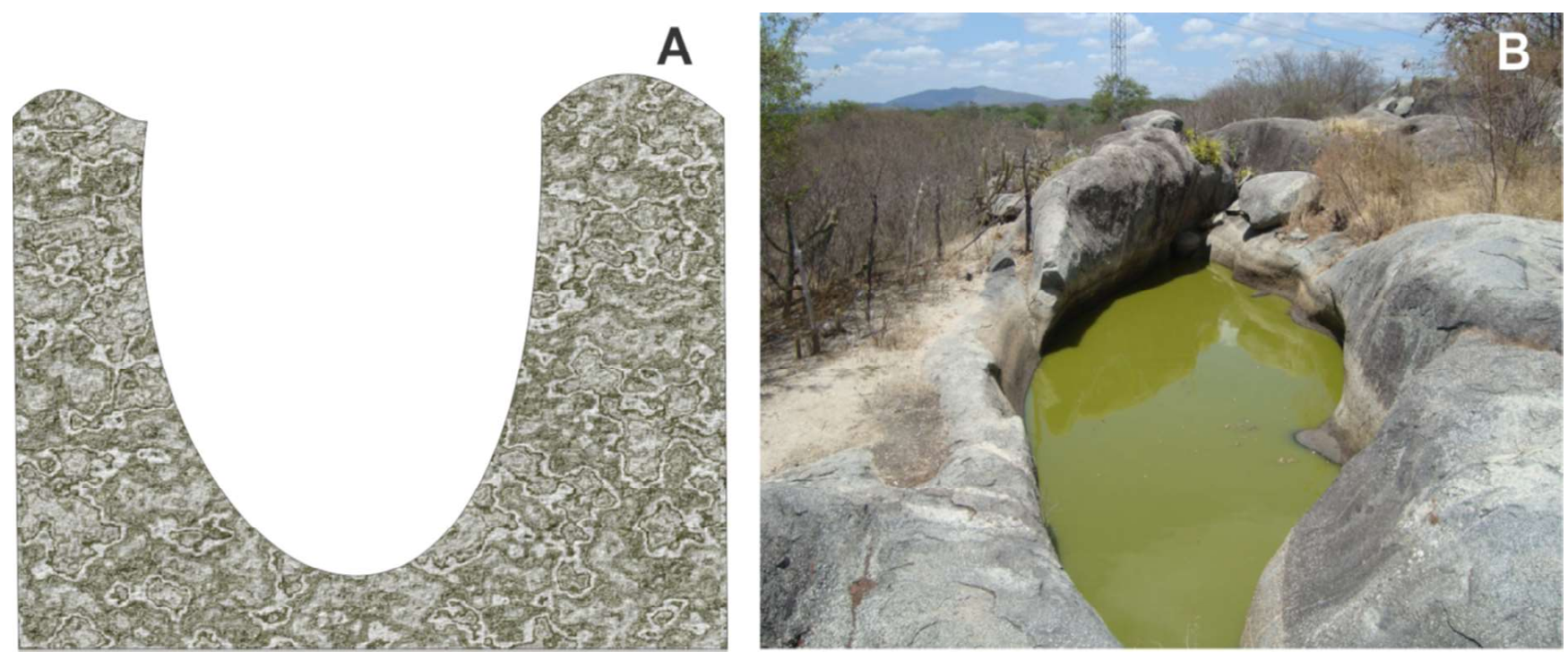

Figura 5 - Marmita com morfologia em caldeirão ou poço. A) Seção esquemática; B) Marmita em Fazenda Nova.

3. Marmita de fundo côncavo ou panela: São seções hemisféricas, e se desenvolvem em superfícies suavemente inclinadas (Figura 6). Em muitos casos não possuem exutório definido, entretanto, quando este existe, exibe uma morfologia estreita.

4. Marmita em poltrona: Desenvolvida em superfícies sua- vemente inclinadas $\left(20^{\circ}-30^{\circ}\right)$, possui uma seção transversal assimétrica segundo a linha máxima da encosta (Figura 7). A parede superior da marmita possui maior altura em relação à parede inferior, onde se encontra o exutório. A sua origem deve-se ao intemperismo diferencial ao longo de intersecção ao longo de planos de fraqueza da rocha.

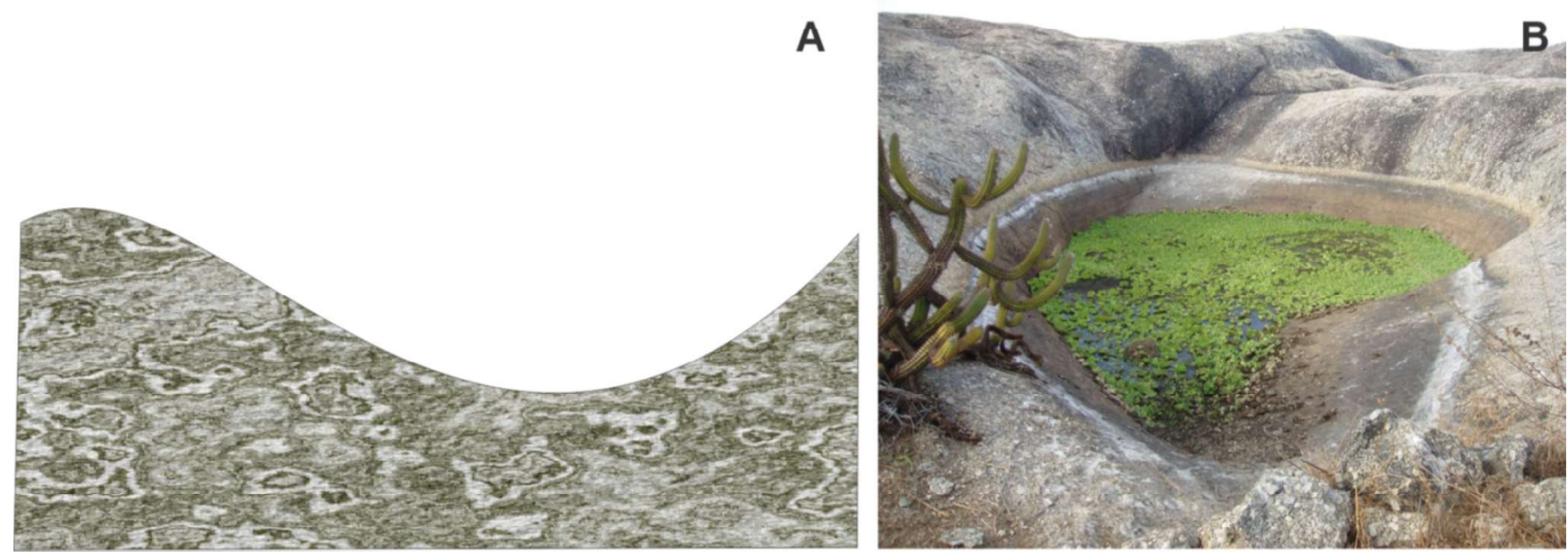

Figura 6-Marmita de fundo côncavo ou panela. A) Seção esquemática; B) Marmita em Fazenda Nova. 

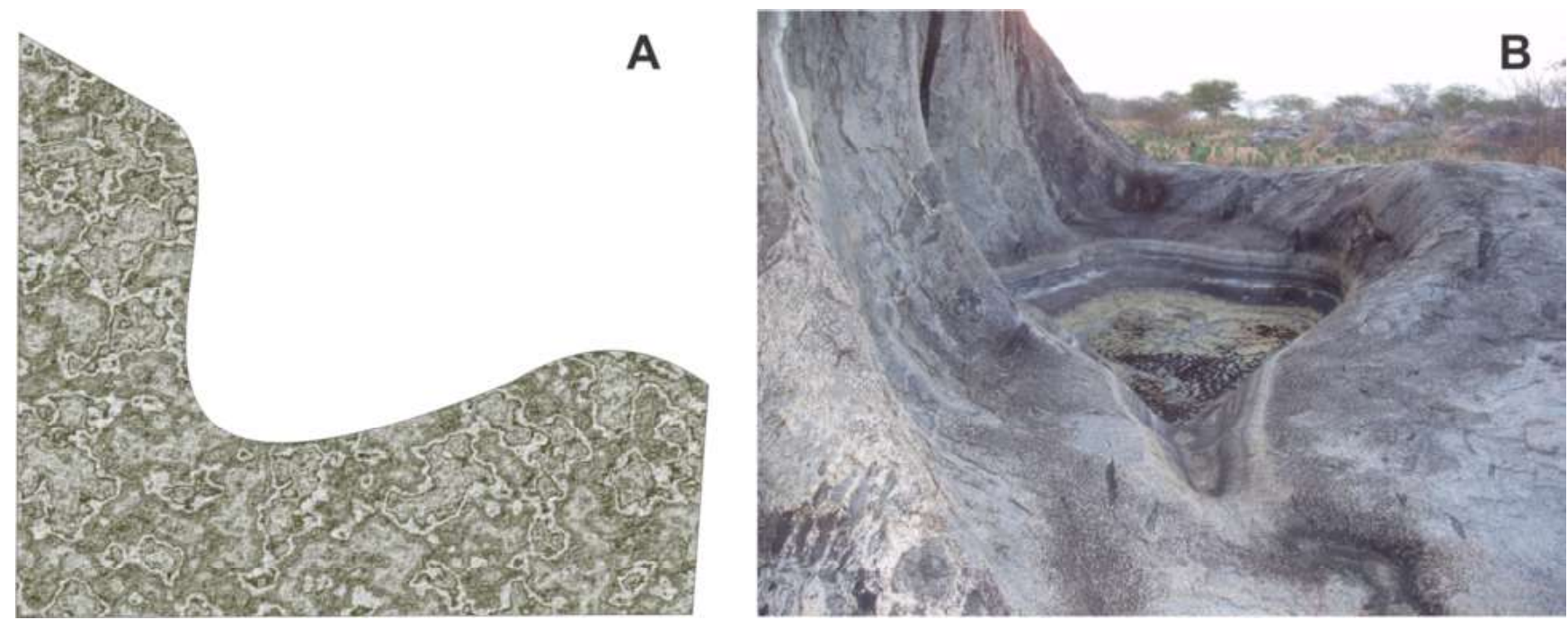

Figura 7 - Marmita em poltrona. A) Seção esquemática; B) Marmita em Fazenda Nova.

5. Marmita de bordas suspensas e assimétricas: Se desenvolve em superfícies rebaixadas, apresentando fundo que varia de côncavo a plano. Com o aumento progressivo da profundidade, as paredes da marmita apresentam uma ação corrosiva de solapamento, devido à permanência de água no seu interior, fazendo com que a reação química atue lateralmente para o interior da depressão, originando bordas suspensas (Figura 8).

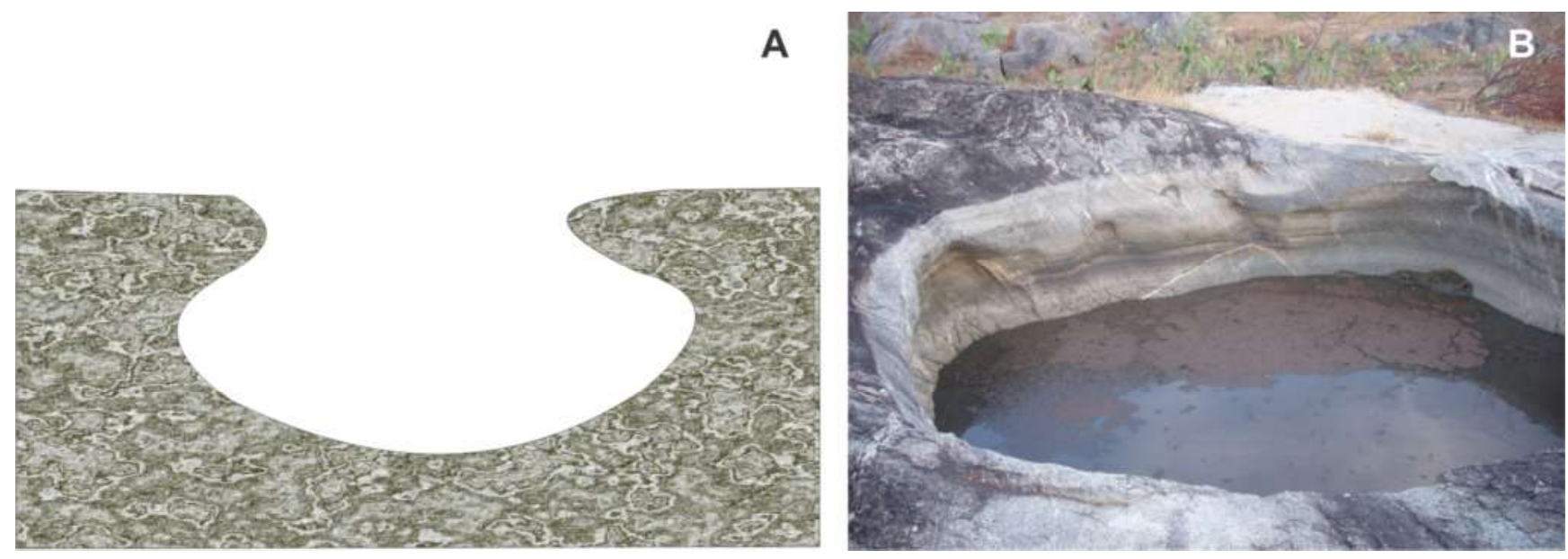

Figura 8-Marmita de borda suspensa. A) Seção esquemática; B) Marmita em Fazenda Nova.

Todas as formas descritas variam em tamanho, possuindo diâmetro superior à profundidade, evidenciando a ocorrência de zonas de intercessão de linhas de fraturas verticais com planos das juntas de alívio de pressão subparalelos à superfície do terreno, o que facilitou a penetração horizontal da água, favorecendo o crescimento lateral da marmita em detrimento de sua profundidade.

A partir do mapeamento da ocorrência de marmitas em Fazenda Nova e análise morfométrica da rede de drenagem, Silva et al. (2009) observaram que as marmitas encontram-se inseridas em áreas de média e alta densidade de drenagem, índice que reflete o alto volume do escoamento superficial atual, após a remoção de qualquer manto de alteração em suas proximidades.

Sendo assim, os autores sugerem que as marmitas que se encontram nas áreas de alta densidade de drenagem são aqueles inseridos próximos aos plainos aluviais, indicando que, provavelmente, estes sempre possuíram uma alta densidade de drenagem capaz de erodir o leito rochoso dando origem às depressões, e a atual ineficácia de erosão da drenagem reflete a cobertura superficial existente associada à baixa atividade pluviométrica do atual clima semiárido; ao contrário das 
marmitas encontradas em inselbergs, que tiveram sua evolução condicionada por erosão diferencial através do ataque da umidade nas zonas de fraqueza litoestrutural, explicando assim sua ocorrência em áreas de média densidade de drenagem.

\section{Marmitas como Ferramenta para Reconstrução Ambiental no Semiárido Pernambucano}

$\mathrm{Na}$ área de Fazenda Nova a sedimentação quaternária encontra-se, em sua maioria, associada à ocorrência de marmitas em virtude destes constituírem setores de armazenamento de sedimentos na paisagem semiárida aqui considerada.

A marmita da Fazenda Logradouro apresenta formato em caldeirão, com diâmetro superior à profundidade ( $27 \mathrm{~m}$ de cumprimento $\mathrm{X} 8,90 \mathrm{~m}$ de largura), associada a um granito pórfiro, e geomorfologicamente restrito à ocorrência de formas residuais sob a forma de inselbergs (Figura 9).

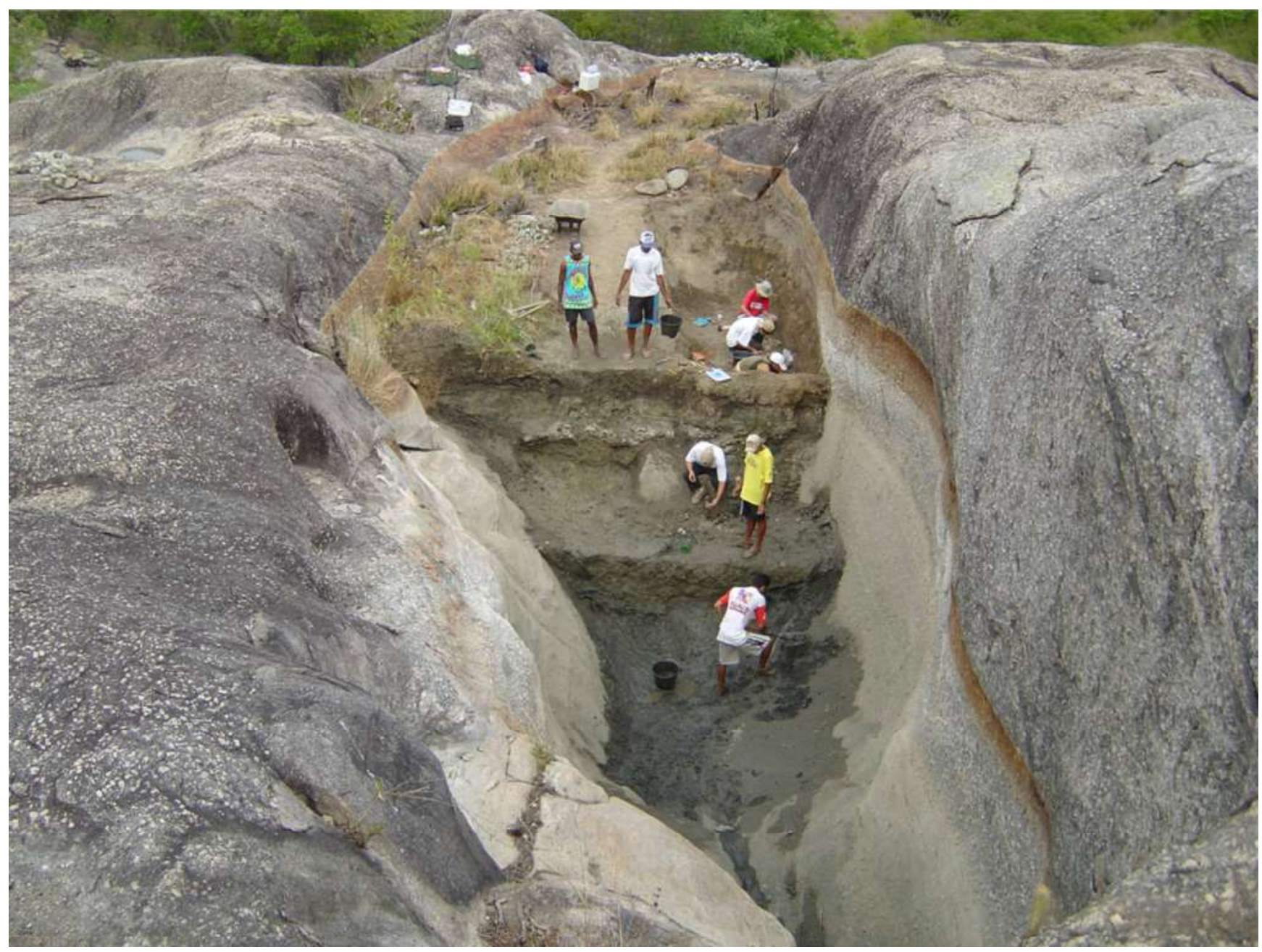

Figura 9 - Marmita da fazenda Logradouro em Inselberg

O depósito que preenche a marmita apresenta espessura de 3,20 metros da base ao topo, exibindo quatro unidades estratigráficas distintas. A coleta ocorreu da base do pacote sedimentar até o topo, de acordo com as unidades estratigráficas observadas em campo. Com base em evidências sedimentológicas e na datação por Lumi- nescência Oticamente Estimulada (LOE), foi possível reconstruir, qualitativamente, os diversos cenários da dinâmica geomorfológica responsável pelo preenchimento da marmita estudada. As concentrações de radioisótopos medidos e idades finais foram agrupadas na tabela 01 para uma melhor visualização dos resultados. 
Tabela 1: Distribuição anual de Th, U, K e cálculo das idades finais das cinco amostras do tanque da Fazenda Logradouro, Fazenda Nova.

\begin{tabular}{|c|c|c|c|}
\hline Parâmetros & Incó 140/1A & Incó 160/1A & Incó 190/1A \\
\hline Th (ppm) & $3,333 \pm 0,120$ & $3,390 \pm 0,120$ & $4,503 \pm 0,162$ \\
\hline U (PPM) & $2,095 \pm 0,108$ & $2,465 \pm 0,111$ & $2,121 \pm 0,180$ \\
\hline K (\%) & $0 \pm 0$ & $0,256 \pm 0,037$ & $0,139 \pm 0,020$ \\
\hline Dose Anual ( $\mu \mathrm{Gy} /$ ano $)$ & $1.040 \pm 37$ & $1.403 \pm 76$ & $1.277 \pm 79$ \\
\hline$P(\mathbf{G y})$ & 61,25 & 63,09 & 25,28 \\
\hline Idade LOE BP (ano) & $58.900 \pm 5.000$ & $45.000 \pm 4.700$ & $19.800 \pm 2.200$ \\
\hline
\end{tabular}

Analisando em escala temporal a estratigrafia do depósito da marmita foi possível reconstruir qualitativamente os cenários de deposição responsáveis pelo seu preenchimento, percebendo-se que alguns eventos estão relacionados a ritmos climáticos já conhecidos para o Nordeste do Brasil desde o Pleistoceno Superior (Figura 10).

A unidade basal é marcada por uma remoção das

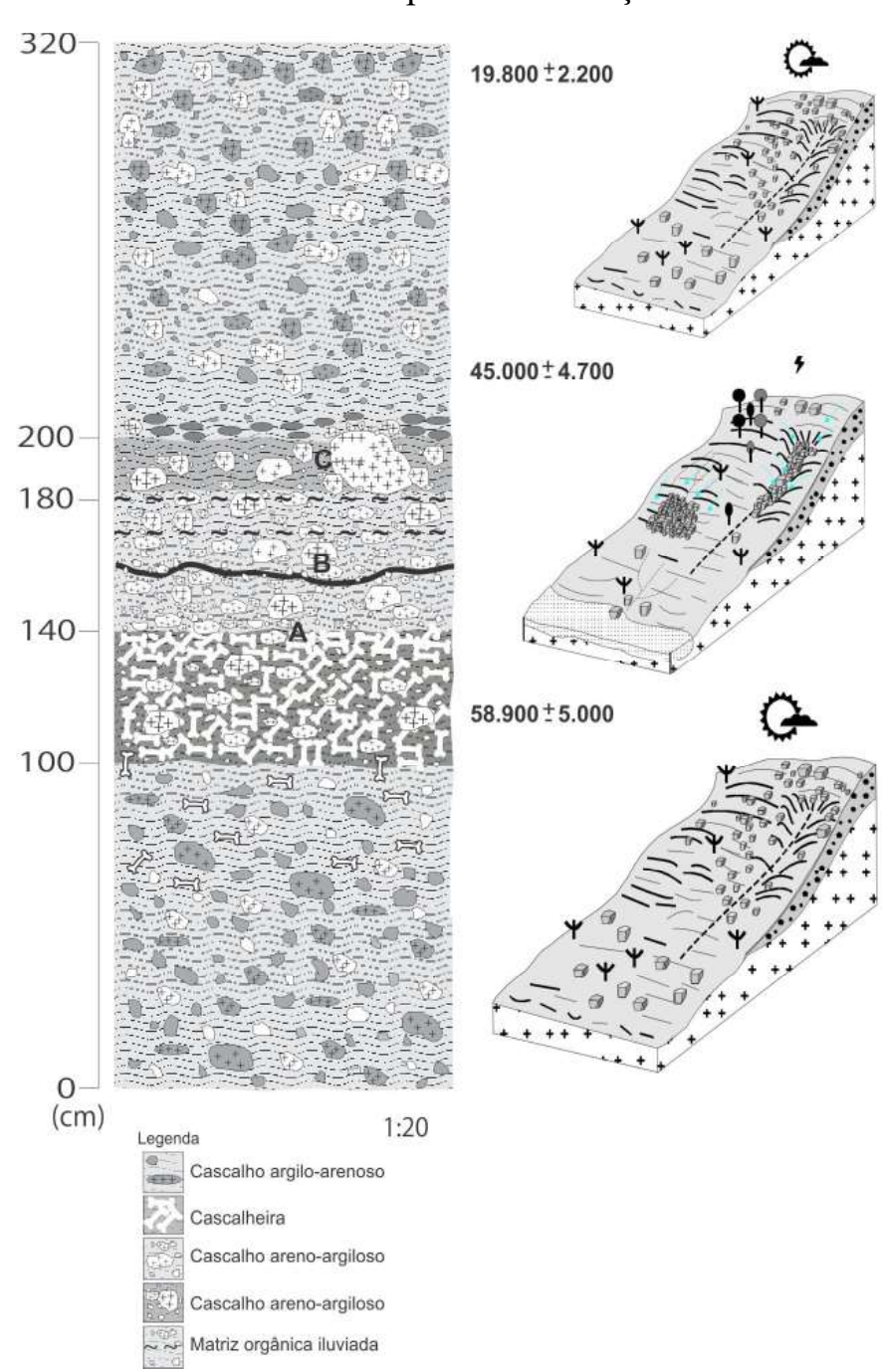

coberturas residuais do entorno da marmita por fluxos de detritos de baixa viscosidade associados, provavelmente à atuação de sistemas meteorológicos convectivos em períodos de aridez concernentes ao antepenúltimo estadial sob vegetação de caatinga arbóreo-arbustiva, que serviu como um anteparo para os clastos maiores liberando apenas as frações grossas.

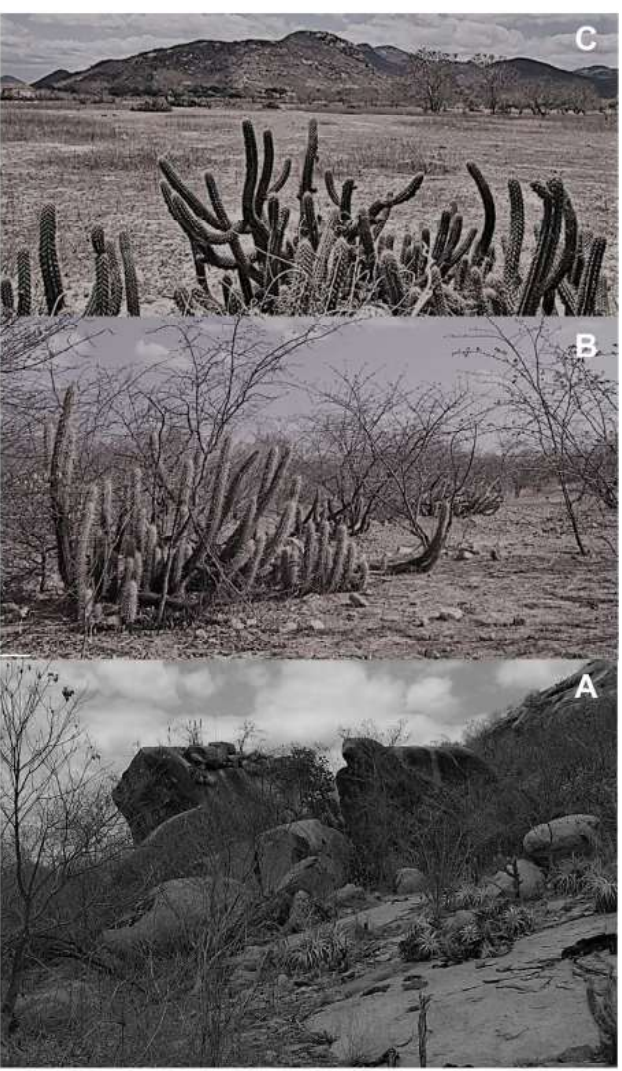

Figura 10 - Ilustração da representação climática durante os cenários de deposição com base na estratigrafia e cronologia das amostras (Modificado de Corrêa, 2001). 
Durante o penúltimo interestadial, a cerca de $58.900 \mathrm{AP}$, a paisagem foi marcada por uma remobilização maciça dos fragmentos clásticos das coberturas superficiais. Este evento está associado a uma cobertura vegetal aberta após período de secura prolongada deixando disponível sobre a superfície apenas os materiais mais grossos (ossos da megafauna e fragmentos de rochas) sendo removidos por movimentos de massa sob condições torrenciais, dando origem a uma cascalheira que posteriormente se converteria em conglomerado sob cimentação carbonática. Esta interpretação está em concordância com a formação de colúvios ligados a fluxos de detritos na região do vale do Rio Carnaúba, Seridó potiguar, estudado por Mutzenberg (2007), confirmando assim, a ocorrência de um episódio de reumidificação com fortes tempestades convectivas.

No penúltimo estadial do Pleistoceno, com temperaturas rebaixadas e predominância de períodos bastante secos em relação à fase anterior, eventos isolados de alta precipitação promoveram a remoção dos materiais rudáceos para o eixo da marmita. $\mathrm{O}$ evento datado em 45.000 AP, reforça a interpretação de eventos ocasionais de alto grau pluviométrico inseridos em um clima mais frio e seco durante este período.

Existiu ainda um período mais seco relacionado ao UMG, o que corresponderia a uma pausa na sedimentação terrígena e formação de carbonato de cálcio. A ocorrência de longos períodos de extrema aridez seguidos de períodos com precipitação, proporcionou oscilações mais ou menos rápidas ou pronunciadas do nível d'água favorecendo a carbonatação através da mobilidade do carbonato de cálcio no perfil. Datações por ${ }^{14} \mathrm{C}$ em 19.400 AP para o cimento carbonático, realizado por Alves (2007), permite inferir que a bacia não funcionou como área de estocagem de sedimento durante o último interestadial.

O UMG na área foi marcado por uma nova remobilização dos mantos de intemperismo relacionada a um clima provavelmente mais frio e seco com eventos de chuvas sazonais de alta magnitude, a cerca de 19.800 AP. Eventos de coluvionamento associados a uma reumidificação do ambiente no UMG encontram-se bem marcado por Corrêa (2001) para a Serra da Baixa Verde, Mutzemberg (2007) para o vale do Rio Carnaúba, RN e Corrêa et al (2008) para Brejo da Madre de Deus. Estas evidências corroboram a hipótese da ocorrência de chuvas torrenciais isolados durante o UMG para o Nordeste do Brasil, que então estava sob um clima semiárido severo.

Eventos contemporâneos de invasão do ar polar sobre baixas latitudes tropicais como o evento "Poço dos Andes" ocorrido em 1975, responsável por intensa onda de frio nas áreas afetadas pelo anticiclone polar móvel que ocasionou fortes e persistentes chuvas frontais para o saliente nordestino, demonstram que a ciclicidade da circulação atmosférica atual pode servir como análogo ao entendimento de eventos extremos de cunho climático regional ocorridos desde o final da última glaciação.

Valores isotópicos $\delta^{13} \mathrm{C}(\%)$ da matéria orgânica do solo (MOS) para o depósito realizado por Alves (2007) demonstraram variações de enriquecimento alternado por empobrecimento isotópico $(-22,7 \%$ a $18,8 \%$ ) após $45.000 \mathrm{AP}$, indicando que a vegetação passou por mudanças vegetacionais entre $\mathrm{C}_{3}$ e $\mathrm{C}_{4}$, e o atual bioma caatinga foi estabelecida na área a partir de $19.800 \mathrm{AP}$, devido à mistura de vegetação de plantas do tipo $\mathrm{C}_{3}$ e plantas CAM, como Bromeliáceae, Cactaceae, Crassulacear, Euphobiaceae e gramíneas.

\section{Considerações Finais}

O resultado da análise morfológica das marmitas demonstrou que, num primeiro momento, a dinâmica geomorfológica da paisagem de Fazenda Nova esteve estreitamente relacionada com a origem e desenvolvimento das marmitas, que ora esteve condicionada por erosão diferencial através do ataque da umidade nas zonas de fraqueza litoestrutural; posteriormente esteve condicionada por escoamento superficial, após a remoção do manto de alteração.

No Quaternário tardio, a evolução ambiental para a área de Fazenda Nova foi baseada na análise morfoestratigráfica do depósito da marmita da Fazenda Logradouro. O depósito que preenche a marmita foi derivado por sedimentação gravitacional do tipo fluxo de detrito, sob condições torrenciais, evidenciando que este registro teve sua gênese associada a ciclos de pedogênese/morfogênese sob diversas combinações de semiaridez atuantes na área.

As idades obtidas para os três níveis estratigráficos datáveis atestaram uma dinâmica episódica de remoção dos mantos de alteração, com pulsos bem marcados, atestando que a marmita funcionou como área de estocagem de sedimento durante episódios de maior energia do clima para o sistema erosivo/deposicional, controlado 
pelas mudanças climáticas regionais ocorridas desde o penúltimo máximo glacial.

A interpretação da dinâmica geomorfológica através do registro sedimentar encontrado na marmita da fazenda Logradouro forneceu bases para a elucidação de interações entre as mudanças temporais de longo e curto prazo nos processos geomorfológicos no Quaternário tardio na região, cujas repercussões ainda são visíveis na paisagem. Entretanto, a principal dificuldade dessa proposta incide na natureza intrínseca do material, pois os depósitos na forma que se encontram na paisagem, representam apenas uma pequena parcela dos materiais originais que conseguiram permanecer incólumes às perturbações decorrentes das mudanças ambientais da ordem de centenas a milhares de anos.

\section{Referências Bibliográficas}

ALVES, R. S. Os Mamíferos Pleistocênicos de Fazenda Nova, Brejo da Madre de Deus, Pernambuco, Brasil. 2007. 163f. Dissertação (Mestrado em Geologia) - Departamento de Geociências, Universidade Federal de Pernambuco, Recife. 2007.

BARRETO, A. M. F. et al. Os depósitos de cacimbas de Pernambuco: aspectos geomorfológicos, geológicos, paleontológicos e paleoambientais. In: XLII Congresso Brasileiro de Geologia. Minas Gerais, Resumos...Minas Gerais: Sociedade Brasileira de Geologia. 2004. p 1-2.

BIGARELLA, J. J. et al. Estrutura e Origem das Paisagens tropicais e Subtropicais. Florianópolis: Editora da UFSC, Volume 1. 1994, 426p.

CAMPBELL, E.M. Granite Landforms. Journal of the Royal Society of Western Australia, 80(3). p.101-112, 1997.

CHRISTOFOLETTI, A. A variabilidade espacial e temporal da densidade de drenagem. Not. Geomorfológica. 21(42). P. 3-22, 1981.

CORRÊA, A. C. B. Dinâmica geomorfológica dos compartimentos elevados do Planalto da Borborema, Nordeste do Brasil. 2001. 386f. Tese. (Tese de Doutorado) - Instituto de Geociências e Ciências Exatas, Universidade Estadual Paulista “Júlio de Mesquita Filho”, Rio Claro. 2001.

CORRÊA, A. C. B.; SILVA, D. G.; MELO, J. S. Utilização dos Depósitos de Encostas dos Brejos Pernambucanos como Marcadores Paleoclimáticos do Quaternário Tardio no SemiÁrido Nordestino. Mercator. Vol.14, p.101-121, 2008.
DOMÍNGUEZ-VILLAR, D. Early formation of gnammas (weathering pits) in a recently glaciated area of Torres del Paine, southern Patagonia (Chile). Geomorphology. Vol. 76, p.137-147, 2006.

EMBRAPA. Zoneamento Agroecológico do Estado de Pernambuco - ZAPE. Recife: Embrapa Solos/Governo do Estado de Pernambuco - Secretaria de Produção Rural e Reforma Agrária, 2001. CD-ROM. (Embrapa Solos. Documentos, 35), 2001.

GOMES, H. A. et al. Geologia e Recursos Minerais do Estado de Pernambuco. Brasília: CPRM, 2001. 215p.

GUTIÉRREZ, M. Climatic Geomorphology. Elsevier Science \& Technology, 2005. 774p.

MUTZENBERG, D. S. Gênese e ocupação pré-histórica do Sítio Arqueológico Pedra do Alexandre: uma abordagem a partir da caracterização paleoambiental do Vale do Rio Carnaúba-RN. 2007. Dissertação (Mestrado em Arqueologia). Departamento de Arqueologia, Universidade Federal de Pernambuco, 2007. 142p.

NETOFF, D. I.; CHAN, M. A. Aeolian activity at a giant sandstone weathering pit in arid south-central Utah. Earth Surf. Process. Landforms. V. 34, p.99-108, 2009.

OLIVEIRA, E. V.; BARRETO, A. M. F.; ALVES, R. S. Aspectos sistemáticos, paleobiogeográficos e paleoclimáticos dos mamíferos quaternários de Fazenda Nova, PE, nordeste do Brasil. Journal of Geoscience. V. 5 (2), p.75-85, 2009.

PAULA-COUTO, C. Fossil pleistocene to sub-recent from Northeastern Brazil. I - EdentataMegalonychidae. Anais da Academia Brasileira de Ciências. V.52 (1), p.143-151, 1980.

PARSONS, R. L.; HEAD III, J.W.; MARCHANT, D.R. Weathering Pits in the Antarctic Dry Valleys: Insolation-Induced Heating and Melting, and Applications to Mars. Lunar and Planetary Science. V. XXXVI, p.1138-1139, 2005.

ROLIM, J. L. Paleontologia e Estratigrafia do Pleistoceno Continental do Nordeste Brasileiro "Formação Cacimbas". 1974. Dissertação (Mestrado em Geologia) - Departamento de Geociências, Universidade Federal do Rio Grande do Sul, 1974. 117p.

SHAKESBY, R. A.; MATTHEWS, J. A. \& OWEN, G. The Schmidt hammer as a relative-age dating tool and its potential for calibrated-age dating in Holocene glaciated environments. Quaternary Science Reviews. V. 25, p.2846-2867, 2006.

SILVA, J. L. L. Reconstituição Paleoambiental Baseada no Estudo de mamíferos Pleistocênicos de Maravilhas e Poços 
das Trincheiras, Alagoas, Nordeste do Brasil. 2008. Tese (Doutorado em Geologia) - Departamento de Geociências, Universidade Federal de Pernambuco, 2008. 240p.

SILVA, D. G.; MELO, R. F. T.; CORRÊA, A. C. B. A Influência da Densidade de Drenagem na Interpretação da Evolução Geomorfológica do Complexo de Tanques do Município de Brejo da Madre de Deus - Pernambuco, Nordeste do Brasil. Revista de Geografia. v. 26 (3), p.294-306, 2009.

TWIDALE, C. R. Granite Landforms. Amsterdam: Elsevier Scientific Publishing Co., 1982. 372p.
VIDAL ROMANÍ, J. R.; TWIDALE, C.R. Formas y Paisajes Graníticos. A Coruña: Universidade da Coruña, 1998. 411p.

VIDAL ROMAÍ, J. R.; RODRIGUEZ, M. V. Types of granite cavities and associated speleothems: genesis and evolution. Nature Conservation. V. 63, p.41-46, 2007.

VIEIRA, A. Análise de Formas do Modelado Granítico de Pormenor na Serra de Montemuro: Factores de Génese e Evolução das Pias. In: VII Simpósio Nacional de Geomorfologia. São Paulo: Tecart, 2008. p. 3860-3875.

WORTH, R. H. Worth's Dartmoor. David and Charles, Newton Abbott. 1953. 553p. 